\title{
Miguel \\ "Defensio fidei” de Francisco Suárez y su conflicto con Jacobo I
}

Anxo Pena

González

Universidad

Pontificia de

Salamanca,

España

mapenago@upsa.es

Recibido: 20.11.17

Aceptado: 23.02.18

\section{Francisco Suárez's "Defensio fidei" and his conflict with Jacob I}

Resumen: La "conjuración de

la pólvora" sirvió a Jacobo I para argumentar el Juramento de fidelidad de los católicos ingleses. La reflexión al respecto se introduce, a un mismo tiempo, por los vericuetos de la reflexión teológica y del pensamiento político. En concreto, la condena de Suárez por parte del Parlamento de París, en 1614, es vista - desde el contexto inglés y francés - , como una intromisión de este en los intereses del Estado. Suárez, por su parte, pretende hacer dialogar la Apología del rey con la situación a la que tendrán que enfrentarse los católicos ingleses y la negativa por parte del papa a la misma. Se entrecruzan dos visiones y comprensiones opuestas: una de índole político, frente a una posición de carácter más amplio, sustentada en un pensamiento, que será la del Doctor Eximio. Suárez, lejos de defender simplemente la postura del papado, intenta poner las bases de lo que más tarde podrá denominarse como libertad de conciencia.

Palabras clave: Libertad religiosa; soberanía popular; juramento.
Abstract: The "gunpowder conjuration" allowed Jacob I to justify the English Catholics Oath of Fidelity. His reflection about it is introduced through the narrow paths of the theological and political thought. In fact, the sentence given to Suárez by the French parliament in 1614 is considered, in the British and the French contexts, as a meddling of the institution in the interests of the State. Suárez aims to create a dialogue between the King's Defence and the situation British Catholics would have to face, as well as the Pope's negative response to it. In this way, two opposite views are intertwined: one, of a political nature, and the other with a broader character and sustained in the thought of the Pope. Far from defending the Pope's position, Suárez tries to settle the bases of what later would be known as freedom of conscience.

Keywords: Freedom of religion; popular sovereignty; oath. 
Entre los años 1606-1607 se da un paso adelante en la ruptura definitiva entre Inglaterra y Roma'. En 1606, el rey Jacobo I de Inglaterra imponía a sus súbditos católicos un Juramento de fidelidad (Jacobo I, 1609), por medio del cual debían declarar que era el soberano legítimo y supremo del reino, por lo que ningún otro poder extranjero tenía jurisdicción para interferir en el gobierno del Estado y, lo que podía ser más importante, que nadie tenía autoridad para condenarlo; obligando a sus súbditos a una obediencia que iba más allá de los límites de la responsabilidad y decisión personal². Frente a esta posición, Suárez sostendrá que la libertad es aplicable a cada individuo o a una comunidad, ya fuera simplemente de un individuo o de un Estado ${ }^{3}$.

La cuestión no tenía parangón en otras épocas. Se habían producido abusos constantes de la autoridad medieval, pero aquello quedaba ya muy lejos. El juramento era una práctica medieval de corte sacral, que ponía de manifiesto los deberes mutuos existentes entre señores y vasallos, pero que en la propuesta del soberano inglés cambiaba de contenido, pretendiendo garantizar la supremacía, autonomía y seguridad del propio monarca, así como la no injerencia de otros príncipes en su territorio. No era fácil justificar la invasión temporal del poder político en el terreno de las libertades naturales del individuo, pero esta propuesta permitía que aquellos que ostentaban el poder se atribuyeran derechos que no les correspondían, como ya había hecho Enrique VIII o había expresado el propio Maquiavelo.

El juramento rompía con la práctica del concepto clásico de contrato, apareciendo como algo unilateral y determinado por una fuerte coacción. Se pretendía garantizar la autonomía, supremacía y seguridad personal del monarca. Era una muestra temprana de absolutismo en el contexto europeo y una injerencia en el fuero interno de un pueblo. Por razón de Estado y en función de la soberanía, difícilmente se podía negar la legitimidad del juramento y la independencia absoluta de los príncipes, pero elaborarlo con tal unilateralidad suponía una nueva comprensión política, en la que había una cuidada atención acerca de las consecuencias deducibles del mismo.

En el juramento se exigía que los católicos reconocieran expresamente que sobre el rey legítimo de aquellas tierras el papa no tenía autoridad alguna para deponerlo ni tampoco sobre los bienes de sus reinos; aún menos para autorizar a otro príncipe extranjero la intervención. El texto resultaba elocuente:

reconozco, professo, testifico y declaro que nuestro soberano señor el Rey lacobo es legítimo y verdadero Rey deste Reyno y de todos los demás señoríos y tierras de su Magestad. Y que el Papa, ni de su propia autoridad, ni de otra alguna de la Yglesia o Sede Romana, por otros medios con otra persona quien quiera, tiene algún derecho o potestad para deponer al Rey o sus tierras, ni para hazerles daño alguno, ni para absolver qualesquier súbditos y vassallos suyos de la devida sujeción y no obediencia o para dar a qualquier dellos licencia o facultad para tomar armas, alborotar el pueblo o intentar alguna violencia en perjuyzio de su Real persona, estado o gobierno, o en daño de algunos vassallos suyos que viven dentro de sus señoríos ${ }^{4}$.

Se hacía hincapié en que los súbditos no podían levantarse en armas contra su rey. Al mismo tiempo implicaba también, que contra lo expuesto en las excomuniones publicadas o que se pudieran dictar contra el rey y sus súbditos, ellos permanecerían fieles a su soberano, obligándose a defenderlo contra los príncipes

\footnotetext{
${ }^{1}$ Esta se había hecho definitiva con la excomunión, en 1571, de Isabel - la hija de Ana Bolena - por parte del pontífice Pío V.

2 "...tamen cum indictum bellum non sit, negari non potest, quin Pontifex contra bonos mores, et consuetu-dinem principium, maxime christianorum, peccarit vehementer, cum me inauditum condemnarit; quod qui-dem fecit, partim me persecutoribus annumerando (ut ex eo, quod cohortatur catholicos suos ad martyrii glo-riam aspirare, non obscure innuitur) partim imperando abstineant; quod dum detrectant, fidelitatem suam profiteri recusant" (Suárez, 1978, De iuramento fidelitatis, p. 291).

3 "Quod enim illi de libertate uniuscuiusque hominis et servitute illi opposita dicunt, eadem ratione in perso-na mixta seu ficta unius communitatis seu civitates humanae verum habet" (Suárez, 1965, Defensio fidei III. I., p. 25). En adelante citamos como: Defensio fidei, seguido del capítulo, número y la página de la presente edición.

4 "Las leyes nuevamente hechas en el Parlamento de Inglaterra este año de 1606 contra los católicos ingleses, que llaman recursante, traduzidas de su original impresso en inglés" (Suárez, 1979, De luramento Fidelitatis, p. 517).
} 
extranjeros que intentaran cualquier maniobra ${ }^{5}$. Debían, además, declarar como herejía y doctrina condenable el sostener que el asesinato de los príncipes excomulgados era lícito ${ }^{6}$. La cuestión era delicada, ya que la mayoría de los autores del momento consideraban que el Romano
Pontífice tenía derecho de soberanía sobre el reino de Inglaterra por ser feudatario, fiduciario y tributario de la Sede Apostólica ${ }^{7}$. Esta lectura era lo que realmente preocupaba a Jacobo I, que intentará salvarla por medio de una argucia jurídicå ${ }^{8}$.

\section{El "Juramento de fidelidad" de Jacobo I}

El juramento fue llevado a efecto después de la "conjuración de la pólvora" (1606), intentando poner freno a cualquier forma de levantamiento. A Jacobo I le preocupaban las doctrinas acerca del regicidio, defendidas por diversos teólogos católicos y que se ponían en confrontación directa con la visión protestante, que predicaba o defendía que el rey recibía el poder directamente de Dios. Por este motivo, luchará personalmente y querrá que el Parlamento acepte sus ideas sobre el derecho divino y hereditario de los reyes.

El Juramento de fidelidad se encontraba a caballo entre dos realidades complejas y de difícil conciliación: lo político y lo religioso. No era fácil delimitar a cuál de las dos cuestiones obedecía. Jacobo I intentará politizar la interpretación, evitando que fuera visto como un problema religioso. No se trataba tanto del poder universal del papa a defender y conservar la fe cristiana, cuanto del derecho de la Sede Apostólica sobre la Corona de Inglaterra. Los límites entre una y otra cosa, como se puede intuir, no eran tan evidentes.
El católico que rechazara el Juramento se exponía a prisión perpetua y a la confiscación de sus bienes. Como es de suponer, esto tuvo como resultado una sangrienta persecución, que no respondía tanto al soberano en sí, cuanto a la estructura de premios que se había creado para el cumplimiento del juramento. Dicha persecución, entre 1605-1660, llevó a cabo unas sesenta ejecuciones. Al crimen de sedición de unos pocos, aquellos que habían promovido la conjuración, se respondía desde el Parlamento con esta ley ${ }^{9}$. El Juramento se convertía en un arma de sumisión política.

No incluía ningún artículo de fe ni conclusiones teológicas. La conciencia general era que el papa no podía obligar a los católicos a negarse al juramento, en razón del perjuicio y daño que podía implicar para los individuos y sus familias. En concreto, se prometía fidelidad al rey de Inglaterra y a sus legítimos sucesores, al tiempo que se negaba la autoridad del papa a deponer o matar arbitrariamente. Después de unas tensas negociaciones diplomáticas, Paulo $\mathrm{V}$-en carta del 22

\footnotetext{
${ }^{5}$ Todos estos detalles contaban con una experiencia concreta, en sus antecesores, los Tudor.

6 "Otrosi juro, que de todo mi coraçón aborrezco, abomino y abjuro, como impía y herética aquella dotrina y opinión dañada, (es a saber) que los Príncipes que están descomulgados o privados por el Papa, puedan por sus vassallos a otras qualesquier personas ser lícitamente depuestos y muertos" (Suárez, 1979, De luramento Fidelitatis, p. 518).

${ }^{7}$ La cuestión venía de lejos, cuando el rey Juan sin Tierra, en 1213, había hecho el acto de sumisión y el juramento de fidelidad al Papa Inocencio III, después de negarse a aceptar la elección de Esteban Langton como arzobispo de Canterbury, por lo que será excomulgado, recuperando los reinos de Inglaterra e Irlanda como feudatario del Papa. Junto a ello estaba la conciencia-teoría de la supremacía de la autoridad papal sobre las islas.

${ }^{8}$ Así aparece, en la misma fórmula del juramento: "Item juro en mi conciencia y de todo coraçón, que no embargante qualquier declaración o sentencia de excomunión o de privación, hecha o por hazer del Papa o de sus sucessores, y no obstante qualquier autoridad que procede o puede proceder del o de su silla, contra dicho Rey, sus herederos y sucessores, y no obstante qualquier absolución de los dichos vasallos de su obediencia, yo la prestaré muy fiely lealmente a su Magestad y a sus herederos y sucessores. Y les haré pleito omenaje de les defender con todas mis fuerças contra todas las conjuraciones o otros qualquier insultos, que contra sus personas, coronas y dignidades, por razón o so color de qualquier tal sentencia o declaración o en otra qual-quier manera aconteciere hazerse" (lacobo I, Fórmula del juramento, p. 517).

${ }^{9}$ No cabe duda que, el hecho de que fuera respaldada por el propio Parlamento le daba un valor y proyección mayor.
} 
de septiembre de 1606 al clero y fieles ingleses - definía que, de ninguna manera, los católicos podían prestar dicho juramento, entendiendo que era abiertamente opuesto a la fe cristiana.

Roberto Belarmino, después de un segundo breve donde Paulo $V$ manifestaba haber actuado por su simple y plena voluntad, sostendrá que el juramento era ilícito, sin que admitiera ningún tipo de componendas ni modificaciones. Con el acto de sumisión y el juramento se atentaba contra la verdad católica del primado del papa al hacer que la autoridad de la suprema cabeza de la Iglesia fuera transferida de los sucesores de san Pedro a los de Enrique VIII. El jesuita entendía que la argumentación era tan sutil que nadie podía prometer sumisión civil sin verse antes obligado a renegar del primado de la Sede Apostólica. Con la intervención apologética de Belarmino se definía la postura de los Estados Pontificios, considerando que el juramento era ilícito, inválido e inútil, por lo que no podía obligar la conciencia de los súbditos ${ }^{10}$.

\section{La proyección del problema: su teologización}

No cabe duda de que en este momento, se había producido ya una teologización del problema, dejando de ser una cuestión política para ampliar su horizonte a otros contextos fundamentales para el pueblo, como era - con la importancia que tenía en ese momentola expresión o creencias religiosas. Ahora se debatía también una cuestión religiosa, que podía buscar un cariz teológico. Se trataba de una clara ampliación del problema, que se enmarcaba en la convulsa situación europea. Un conflicto de política interna derivaba en una polémica abierta entre el rey de Inglaterra y el pontífice de Roma. Ante esta situación, algunos doctores de la Sorbona comenzarán a defender públicamente el juramento de fidelidad, mientras que Paulo V - eminente canonista y admirador de Gregorio VII e Inocencio IIIestaba dispuesto a luchar por mantener los derechos de la Sede Apostólica. Para ello, un arma nuevamente utilizada será la bula In Coena Domini, promulgada con solemnidad, contra los que interferían en la apelación a la Sede Apostólica ${ }^{11}$. Paulo $\vee$ veía cómo cada vez eran más frecuentes los conflictos vividos con España y Francia, por razones de competencia, lo que le llevaba también a hacer valer sus derechos, aunque la ejecución de los mismos fuera ya algo complejo.
Por su parte, Jacobo I tenía miedo a los efectos políticos de la excomunión en el contexto europeo. Esta era su verdadera preocupación: la amenaza de invasión y la doctrina del tiranicidio - como hemos dicho- le preocupaban seriamente. Por lo mismo, de manera atenta y política irá invadiendo la esfera de la conciencia privada para asegurar su poder absoluto. Por su parte, Paulo V, desde una posición de partida en la que lo que le preocupaba era lo espiritual, terminará por invadir la esfera política en defensa de la inmunidad eclesiástica, con la diferencia de que la interpretación de la "plenitudo potestatis", recuperada en el contexto de la reforma católica, ya no tenía tan fácil aplicación y, lo que era más importante, era difícilmente aceptada por parte de los soberanos europeos. Ambos querían el monopolio del poder. El juramento de fidelidad, de una preocupación honda, pasaba a convertirse en una excusa y una justificación. La expresión visible se llevó a término por medio de una batalla de panfletos y escritos en defensa de las tesis defendidas por cada cual. La lógica del poder, por lo mismo, degeneraba en abuso de poder.

\footnotetext{
${ }^{10}$ De esta manera, Belarmino atacaba con los mismos argumentos, pero en un claro recurso a la Tradición, que no dejaba de interpretar según le interesaba.

${ }^{11}$ En ella se reunían tradicionalmente las censuras eclesiásticas reservadas al papa, pero que ahora habían sido recuperadas por Pío V (1568) en una aplicación rígida.
} 
El rey de Inglaterra escribirá su Apología presentándose como un teólogo en defensa de los derechos de la Corona ${ }^{12}$. Usando el método y los argumentos escolásticos intenta hacer válida su postura, considerándose a sí mismo como verdadero intérprete de la verdad política y queriendo tranquilizar la conciencia de los católicos que habían prestado el juramento. Era una argucia política en la que se condenaban como delitos la traición, destitución o golpe de Estado, la rebelión o levantamiento en armas, así como cualquier forma de colaboración y acción encaminada contra la vida del monarca.

El juramento tenía su fundamento en el deber de obediencia de todos los súbditos para con su rey y soberano, en virtud del vínculo natural de sangre y nacimiento dentro del territorio nacional. Pretendía sancionar el derecho natural por medio del vínculo sagrado del juramento. Afectaba a todos los súbditos del reino, sin discriminación alguna, y no aceptaba más diferencia que la existente entre aquellos que eran súbditos leales y los que eran traidores. La conciencia quedaba sacramentalmente instrumentalizada a los intereses supremos del monarca. Al mismo tiempo, Jacobo I denunciaba la injusticia del papa al poner en peligro no solo la tranquilidad interna del reino de Inglaterra, sino también la paz y estabilidad de los reinos cristianos. Por otra parte, le preocupaba la concepción y argumentación de Belarmino que, a los perseguidos por el Estado, los convertía en mártires de la fe. Una manera sutil de inducir a la desobediencia civil ${ }^{13}$.

Las tesis del jesuita serán anatematizadas y quedará desautorizado por Jacobo I. La Apología, de manera indirecta, pretendía dar seguridad a muchos católicos que se veían en la disyuntiva y necesidad de hacer el juramento. Por su parte, Belarmino acusaba a Jacobo I de haber renegado de la fe católica, comparándolo con
Juliano el Apóstata ${ }^{14}$. Eran propuestas enfrentadas que hablaban de una ruptura inevitable. Belarmino sustentaba su posición a partir de dos principios fundamentales: el primero ponía de relieve que el poder del rey viene de Dios a través del pueblo y, en segundo lugar, que la comunidad política era el sujeto natural de la soberanía.

Y, por lo mismo, de ese carácter de comunidad política como aquella en la que residía el poder, deducía el derecho del mismo pueblo a la rebeldía, entendiendo que los derechos de este son superiores a los de la monarquía. Estaba reconociendo al pueblo, en caso de tiranía manifiesta, el derecho a la insurrección. Así, la desobediencia civil podía ser un deber de conciencia para los ciudadanos. No cabe duda de que las posiciones de Belarmino, como sucederá luego con las de Suárez, provocaron escándalo y reacciones de profunda virulencia ${ }^{15}$.

El planteamiento de Belarmino parecía un reto al absolutismo de los reyes que dominaban en Europa, representados en la figura diabólica del soberano de Inglaterra. Jacobo I retocará su Apología, publicándola ahora con su nombre, y añadiéndole un largo prólogo que dedica al emperador Rodolfo II conjuntamente con todos los reyes y soberanos de Europa (1609): "Porque todos están interesados en la controversia. Es una causa pública que concierne a la autoridad y dignidad de los reyes que han recibido de Dios, como vicarios y legados suyos, la soberanía política".

Jacobo I se consideraba protector y defensor de la antigua, primitiva y católica Iglesia ${ }^{16}$. En esta segunda edición, la obra se convierte en agresiva y fuertemente grosera, manifestando su pérdida de control y de tacto en el conflicto, lo que hace más comprensible la intencionalidad profunda del juramento.

\footnotetext{
${ }^{12}$ Algo que ya había hecho el mismo Enrique VIII, del que no se puede olvidar que contaba con el título de "defensor de la fe". El título le había sido concedido, en 1521, por un tratado suyo contra Lutero. En este sentido, conviene recordar que Enrique VIII permaneció católico, aunque cismático, hasta su muerte.

${ }^{13}$ Creo que en este tipo de problemáticas y sensibilidad, se pueden intuir los orígenes de la preocupación por la libertad religiosa.

${ }^{14}$ La comparación llevaba a los tiempos de la confesión de Constantino y la declaración oficial del cristianis-mo como religión oficial del Imperio por parte de Teodosio.

${ }^{15}$ Lo que, con el paso del tiempo, quedaría como una teoría propia jesuítica. Piénsese, en este sentido, en las consecuencias que tendrá esto en el reinado de Carlos IV y el extrañamiento de los jesuitas.

${ }^{16}$ La idea entra en el perfil más puro del Humanismo clásico, en el que ya se había ubicado Enrique VIII.
} 
Jacobo I intentará enviar la obra a todos los príncipes cristianos, para ponerlos de su lado y hacer un frente común contra el papa. Por su parte, Paulo V se moverá también diplomáticamente en el sentido contrario. Así, en carta a Rodolfo II, Paulo V, el 14 de agosto de 1609, le indicaba que se negase a aceptarla, prohibiendo su publicación y lectura dentro de sus Estados, si quería conservar la paz y la concordia de sus súbditos. En esta ocasión, el papa quería que el derecho de presentación - contra el que estaba luchando denodadamente desde hacía décadas - se pusiera ahora a su servicio. Cuatro días más tarde, se dirigía al rey católico, pidiéndole que hiciera fracasar el proyecto de Jacobo I. Así siguió en relación a otros territorios, donde la Apología fue recibida con frialdad y hasta con profundo escándalo. Había, por lo mismo, una compensación de fuerzas que respondía a los intereses que cada uno quería defender.
En Francia, aunque el nuncio Ubaldini intentó que fuera rechazada, Enrique IV acepta el homenaje y la misma obra, que entregará a sus teólogos para que fuera refutada de manera cortés y moderada, siendo el único apoyo a Jacobo I, aunque siempre en medio de una fuerte ambigüedad. No cabe duda de que, con el magnicidio del soberano francés el proceso de politización se acelerará, y los hechos discurrirán de una manera concreta.

De esta forma, fueron creados dos grupos ideológicos enfrentados. Por una parte se encontraba el católico, ordenado en torno a la Universidad de Salamanca, con fuertes repercusiones también en Coímbra y Lovaina. Y, en clara oposición al mismo, el protestante que tenía su centro en Leyden, aunque el papel preponderante lo ocuparán las universidades de Oxford y París.

\section{Escándalo y condena de la obra política de Suárez en París}

Con estos antecedentes, Suárez se encontró en el medio de la polémica suscitada por Jacobo I y Belarmino. Él se convertirá en uno de los revulsivos más fuertes del absolutismo político. No se trataba, por su parte, de una preocupación personal, sino que será invitado oficialmente por el papa el 5 de enero de 1610 para intervenir en la controversia, y aunque intentará zafarse de la problemática, no tendrá más remedio que aceptar, por lo que pedirá garantías pontificias en aquello que abordaría ${ }^{17}$. La obra estará terminada en 1612. Así, el 5 de enero, el Secretario de Estado de los Estados Pontificios comunica haber recibido la primera parte del manuscrito. Posteriormente, entre el 24 de noviembre y el 24 de junio de 1613, tienen lugar las autorizaciones civiles y canónicas. Un día más tarde, Suárez dedica a Paulo $\mathrm{V}$ el volumen terminado.
En razón de la celeridad por ver culminada la obra, de la singularidad del encargo y del prestigio del propio autor, ni en Roma ni en Madrid, fue revisada la obra de manera completa por los censores oficiales. La tesis del tiranicidio, defendida por Suárez, provocó escándalo en todos los reinos europeos, generando una fuerte contradicción y expectación. Jacobo la calificará de pestifer liber contra me ex professo scriptus. Suárez no podía eludir el tema central de la polémica que seguía siendo la obediencia o desobediencia civil. Su tesis, sobre el derecho de rebeldía, provocará ondas protestas, particularmente en Francia e Inglaterra.

Unos meses más tarde, en Colonia, tiene lugar una segunda edición. En Francia existía una fuerte expectación, por lo que desde Roma se asegura que

\footnotetext{
${ }_{17}$ Su garantía, con bastante probabilidad, respondía a la libertad de pensamiento con la que se moverán los jesuitas en este momento. Con todo, la teoría estaba vinculada con la tradición castellana donde la soberanía residía en el pueblo y los reyes eran administradores de la misma, por encomienda o contrato con el pueblo.
} 
Suárez no abordaba el conflictivo tema del tiranicidio, que tan delicado resultaba para el rey cristianísimo. Por su parte, Jacobo I enviará una selección de textos buscando lo contrario. En este momento, la obra será denunciada al Parlamento, por lo que teólogos y galicanos de la Sorbona, parlamentarios regalistas y políticos ambiciosos se conjurarán contra la Defensio fidei. Con estos antecedentes, a principios de 1614, el fiscal y abogado general del Reino acusaba ante el Parlamento a Suárez de atentar contra la independencia de la Corona de Francia. Al tiempo que se condenaban las doctrinas del regicidio, se limitaba la autoridad del pontífice ${ }^{18}$.
La sentencia fue pronunciada el 26 de junio, declarando que el libro de Suárez contenía proposiciones escandalosas y subversivas. Se ordenaba que fuera quemado en el patio del Parlamento por el verdugo, como si de un auto de fe se tratara. Se prohibía su impresión, venta y lectura. La sentencia fue ejecutada al día siguiente en presencia de una gran muchedumbre. Y, como sucede en estos casos, tuvo el efecto contrario al que se pretendía, induciendo a una mayor difusión de la obra.

\section{Un pensamiento libre}

Después de presentar la relación histórica de los hechos de manera abreviada, analizando algunas de sus consecuencias políticas y religiosas, entremos ahora a estudiar lo singular y sutil de dicho pensamiento. Teniendo presente que, precisamente por esas características se explica que pudiera generar un fuerte escándalo, no solo entre aquellos que se alineaban en torno a Jacobo $\mathrm{I}$, sino incluso a los que lo hacían en torno a Paulo $\mathrm{V}$ y sus intereses. No olvidemos que, en el fondo, se trataba de un absolutismo monárquico frente a un absolutismo papal.

\subsection{La desobediencia civil}

La cuestión que interesa analizar es si el juramento atentaba contra la conciencia particular del individuo o de la colectividad católica; si entraban en conflicto obediencia y desobediencia civil de manera manifiesta ${ }^{19}$. Desde el marco social y político las autoridades civiles insistían en que se trataba de asegurar la obediencia de los súbditos negando al papa la autoridad para intervenir en los asuntos políticos de Inglaterra; pero, por su parte, el clero anglicano encontraba un recurso para poner freno a los papistas ${ }^{20}$. La situación era tan tensa que el propio Jacobo I condenará a los puritanos que atacaban indiscriminadamente a los católicos. Trono y altar caminaban de la mano en la interpretación inglesa y, si en algún momento la medida del juramento había tenido alguna lógica formal, automáticamente la perdía en razón del fanatismo de la Iglesia nacional de Inglaterra.

\footnotetext{
${ }^{18}$ El fiscal del reino había llegado a las siguientes conclusiones: que fueran declaradas escandalosas y pernicio-sas las doctrinas del libro, por ser contrarias a los sagrados concilios, a los antiguos decretos y a las senten-cias del tribunal; que la obra fuera condenada al fuego, prohibiéndose su publicación, venta y lectura, retirán-dose los fondos de las librerías o imprentas; que el tribunal suplicara a los soberanos que escribieran al papa, para que empleara su autoridad en suprimir tales libros; que fueran citados seis de los principales jesuitas que habitaban en París, para que se presentasen ante el tribunal y oyeran la sentencia, y que se procediera contra los que escribieran, enseñaran y disputaran sobre las teorías defendidas en el libro como criminales de lesa majestad y perturbadores del orden público.

${ }^{19}$ Así se deducía del mismo juramento: "Item creo y en mi conciencia tengo por cosa muy cierta y resuelta que el Papa, i otra persona qualquiera, tenga potestad para me relaxar y absolver deste juramento o alguna parte del. El qual juramento yo confiesso avérseme dado legítimamente y según derecho, con buena y entera autori-dad; y del todo renuncio a todas la indulgencias, relaxaciones y dispensaciones que puede aver en contrario. Todas esas cosas llana y sencillamente reconozco y juro, assí como las palabras suenan y se pronuncian y según el llano y común sentido dellas, sin ninguna equivocación o mental evasión o otra secreta reservación de qualquier género que sea; y esta protestación y reconocimiento hago de todo mi coraçón, verdadera y es-pontáneamente, debaxo de la fe de verdadero Christiano" (Suárez, 1979, De iuramento fidelitatis III. I., p. 518).

${ }^{20}$ El juramento había sido una propuesta del arzobispo de Canterbury, encarnizado beligerante anglicano, al ministro Salisbury, por lo que era evidente que había otros intereses ocultos que ocupaban un papel importan-te (Suárez, 1979, De iuramento fidelitatis IV, 15, pp. 87-88). En el mismo juramento se marcaban una serie amplísima de limitaciones para aquellos católicos que recusaran pronunciar el juramento. Por otra parte, esta praxis se completaba por medio de un edicto real promulgado el 10 de junio de 1606, que desterrase de sus estados a todos los religiosos y sacerdotes católicos ingleses.
} 
Al papa se le negaba la autoridad para deponer o matar arbitrariamente, al tiempo que no podía obligar a los católicos a oponerse a prestar dicho juramento, por las terribles consecuencias que implicaba, de manera práctica, para sus vidas. No había alternativa: martirio o juramento. Por otra parte, este último claramente hacía abstracción de cuestiones dogmáticas, por lo que no planteaba ningún artículo de fe ni conclusiones teológicas, centrándose en unas acciones abiertamente injustas que, de llevarse a efecto, hacía de éstos unos infelices sin ningún tipo de autonomía o capacidad de decisión personal. Se prometía fidelidad al rey de Inglaterra, así como a sus sucesores legítimos, negándoseles cualquier derecho propio como pueblo.

Se consideraba objetivamente que un rey podía solicitar el juramento de sus súbditos, sobre todo cuando esto se pedía de manera "correcta y razonable" ${ }^{21}$. Incluso entendiéndose que había una obligatoriedad del cumplimiento moral del mismo y, también, en relación con la obediencia civil. Sin olvidar los aspectos jurídicos y políticos que estaban imbricados y que hacían referencia a la conciencia de los súbditos ${ }^{22}$.

El juramento, por medio de una fe expresada públicamente, en un momento en el que resultaba socialmente incuestionable, permitía una seguridad mayor en la firmeza de la fidelidad prometida; también en relación con los aspectos socio-políticos. Pero el conflicto surgía desde el momento en que obedecer al monarca de Inglaterra obligaba necesariamente a desobedecer al papa, lo que se convertía en algo ilícito; comprendiéndose que no se podía manifiestamente desobedecer al papa en cuestiones eclesiásticas ${ }^{23}$.

La cuestión se complica todavía más cuando el papa Paulo V, el 22 de noviembre de 1606, prohíbe hacer el juramento y lo repite exactamente un año más tarde con un nuevo breve apostólico. Suárez pondrá de manifiesto que el juramento iba dirigido a buscar la obediencia civil de sus súbditos y, de manera encubierta, también la obediencia espiritual. No se trataba fundamentalmente de un problema de relaciones Iglesia-Estado, sino que hacía referencia a la supremacía de la dimensión religiosa de la vida social sobre la dimensión política ${ }^{24}$. La separación entre Iglesia y Estado, en la segunda mitad del siglo $\mathrm{XVI}$, era una cuestión de primer orden. Por lo que así era también abordada en la búsqueda de una solución y respuesta adecuada a la gravedad de los hechos.

Suárez había dado un paso firme hacia delante poniendo de manifiesto que la superioridad, que podríamos llamar moral de la Iglesia, no significaba de facto una autoridad también jurídica. La Iglesia y los Estados debían aparecer como entidades autónomas en sus respectivas competencias, pero entendiéndose que, tanto una como la otra, estaban obligadas a una sujeción moral. Era función de la Iglesia el definir y concretar las exigencias de dicha moral cristiana y el Estado cristiano, por tanto, debía someterse a dicha praxis moral; lo que hacía que la Iglesia tuviera también un poder político.

\footnotetext{
${ }^{21}$ Suárez, F. (1965). Defensio fidei, Proemium, p. 18.

22 “... illa erit quaedam externa confessio et professio potestatis regis absolute supremae in omni materia et sine ulla limitatione praeter illam quae in ipsis verbir additur de terris eius dominio subiectis. Quae limitatio auget caetera verba, ut sine ulla limitatione dicta intelligantur. Multoque magis id declarant verba sequentia, ubi iam non tecte sed expresse ultra civilem et temporalem obedientiam iuramentum extenditur" (Suárez, 1979, De iuramento fidelitatis II, 3, p. 45).

23 "... con esas palabras no tanto se jura obediencia al rey, como se abjura de la potestad del Papa. Ahora bien, tratar de la potestad del Papa y proponerla como objeto de juramento o de abjuración no es competencia del poder civil y político del rey ni es materia de la obediencia civil que se le debe. Luego esas palabras sobrepa-san evidentemente los límites de la obediencia civil. Primero, porque las palabras mismas están significando algo más que la obediencia civil debida al rey, como ellas mismas evidencian; y segundo, porque el propio acto de exigir tal juramento y de imponer la obligación de profesar esto o aquello respecto a la potestad del Pontífice, es un acto de jurisdicción más que civil, incluso de la mayor jerarquía y no sometida a la potestad del Pontífice. No es competencia del poder civil fijar límites al poder espiritual, sobre todo si se trata del poder de soberanía" (Suárez, 1979, De iuramento fidelitatis II, 3, p. 46).

24 "Accedit quod per illa verba proponitur professio cuiusdam errores contra doctrinam ab universa Ecclesia probatam. Quamvis enim revera materia illa ecclesiastica sit, si doctrina proposita vera esset, utcumque tole-rabilis esset iurisdictionis usurpatio; cum tamen ipsa forma iuramenti errorem contineat et ad illum profiten-dum súbditos compellat, non solum exigit aliquid ultra obedientiam civilem, sed etiam cogit ab agnegandam pontificiam potestatem et ad confidendum aliquid sanae doctrinae contrarium" (Suárez, 1979, De iuramento fidelitatis II, 3, p. 46).
} 
De esta manera se ponía de manifiesto que había una supremacía de la moral y de la conciencia sobre la ley, que se concretaba en que la Iglesia y en el presente caso por medio del papa, dispensaba a los cristianos de la obediencia a Jacobo I, no en virtud de una jurisdicción civil, sino en el pleno ejercicio de una función religiosa que le daba poder para declarar la supremacía de la conciencia sobre la ley, poniendo de manifiesto cómo algunos preceptos de los príncipes resultaban abiertamente pecaminosos ${ }^{25}$.

Suárez, por tanto, siguiendo las doctrinas de Roberto Belarmino daba un paso adelante proponiendo una nueva lectura que se distanciaba de la comúnmente aceptada de las dos espadas. En la teoría política clásica la idea de la revocación del poder acompañaba, como contrapunto, a la transmisión popular, la imperii translatio del mismo, basada en un acuerdo o consenso de los hombres, al pasar del estado de naturaleza a la sociedad civil. Esta idea de la imperii revocatio será la que esté presente en la consumación de la desobediencia civil y a la que responde el propio calificativo civil de la expresión (Cosi, 1984, p. 4).

Un afán político se podía identificar en Jacobo I: apoderarse de las conciencias de los ciudadanos como instrumento para alcanzar o perpetuarse en el poder. Suárez manejaba un concepto de autoridad, al igual que sus coetáneos, sustentándolo en una concepción moral que tenía como efecto concreto la capacidad para imponer obligaciones en conciencia. Planteadas así las cosas, el poder coactivo ocuparía un lugar secundario. Pero la propuesta del soberano inglés argumentaba de una manera totalmente nueva, entendiendo como sinónimos dos conceptos diversos hasta ese momento: autoridad y poder. Lo que ahora ocupará el lugar central será el poder. Así, una concepción moral es sutilmente sustituida por una concepción política, siempre al servicio de unos intereses particulares.
Aun con esta nueva concepción impuesta seguía manteniéndose una estrecha relación entre la esfera de la conciencia y de las convicciones personales, que no tienen que ver con la esfera pública. Se trataba de una defensa de la conciencia individual o grupal, frente a imposiciones injustas de cualquier tipo o contexto que pudieran provenir. La desobediencia civil se configuraba como una de las herramientas fundamentales del Estado de derecho. Llama la atención que fuera en el contexto inglés y con una estructura de gobierno tan consolidada como su parlamentarismo, que se pusiera en marcha un arma tan eficaz. Hacemos hincapié en este detalle, pues pone en evidencia que no se trataba de un problema político, sino religioso. Francisco Suárez afirmará que era una realidad que había comenzado con Enrique VIII, continuando durante los reinados de Isabel y Jacobo. El ejemplo propuesto con gran lógica es el de Thomas More, manifestando que la muerte de aquel hombre justo había sido consecuencia directa de sus creencias (Suárez, 1979, De iuramento fidelitatis, XI, 2, p. 222).

\subsection{El derecho de resistencia}

El derecho de resistencia era una institución histórica, entendida como resistencia contra el poder que, de alguna manera, violaba el derecho que regía en la sociedad política. Respondía a una institución histórica, vinculada con una filosofía teológico-jurídica que predominó en Europa durante siglos. Posteriormente se producirá un cambio conceptual, en el que será sustituido el concepto de autoridad por el poder. Por ello, tradicionalmente se inicia el estudio histórico del derecho de resistencia, durante la Edad Media, con la teoría del tiranicidio. La peculiaridad era que dicho derecho había de ser entendido en un sentido colectivo; como un derecho del pueblo frente al tirano, aunque la ejecución concreta pudiera corresponder a cualquier súbdito, poniendo en claro que no se trata de una intervención arbitraria de índole personal, sino que se sustentaba y apoyaba a partir de una argumentación clásica, especialmente

\footnotetext{
25 "Con las palabras de este juramento no solo se exige de los súbditos obediencia civil, sino también que pro-fesen el error de que el Papa no tiene potestad ni jurisdicción para dictar sentencia de deposición contra el rey por ninguna causa. Por consiguiente, no es verdadera la proposición del rey de que ese juramento no contiene nada que no pertenezca al ámbito de la obediencia meramente civil y temporal. Asimismo, se concluye de aquí que pecan gravísimamente los súbditos que presten este juramento, puesto que profesan y reconocen externamente que el Papa no tiene jurisdicción sobre el rey para dictar contra él sentencia justa de deposición, cualquiera que sea la causa y cualquiera que sea el modo como la dicte, aunque acate el orden que exigiría la justicia natural, caso de no faltar tal poder" (Suárez, 1979, De iuramento fidelitatis II, 3, p. 55).
} 
cuando se quería resistir a un tirano, como usurpador del poder (Suárez, 1979, De iuramento fidelitatis XI, 2, p. 221).

Durante la Escolástica, el derecho de resistencia fue una institución ampliamente conocida. El mismo Juan de Salisbury había intentado conciliar poder temporal y espiritual, estableciendo modos de convivencia para los poderes en conflicto, ya que el gobernante tenía como finalidad una enseñanza ética, denunciando a quienes vivían de las apariencias, sin cumplir el rol que Dios les había encomendado en la tierra. El ius resistendi aparecía en el Medioevo como una alternativa a las disposiciones injustas de los gobernantes, carentes de validez jurídica si no eran la expresión de un contenido de justicia y no contenían un desarrollo de los preceptos de la ley natural. Son conocidas las palabras de san Agustín y de santo Tomás de Aquino condenando como inválidas las leyes humanas positivas injustas (Tomás de Aquino, Suma Teológica II-II, q. 42, a. 2) que, además, se sustentaban en el hecho de que el gobierno debía fundamentarse en la división de la sociedad. Este derecho de resistencia podía, por tanto, autorizar en casos extremos la deposición e incluso la muerte del gobernante tirano.

Pero deponer al tirano exigía el cumplimiento de numerosos requisitos, al tiempo que ponía freno al posible límite utilitarista de la eficacia de los resultados. La conexión de este derecho de resistencia con el pensamiento político escolástico hace que posea, en un principio, un sentido teológico. Aparece como una posible alternativa al incumplimiento del príncipe o gobernante con su obligación de dictar disposiciones justas; concordantes con la ley natural, que no era otra cosa que la ley eterna, hecha presente en la razón de los hombres. El derecho de resistencia era un instrumento humano con una finalidad paralela a la perseguida en otro plano por la Providencia; que miraba a la protección de la ley divina, que se alcanzaba exigiendo la justicia de las leyes positivas dictadas por los hombres qui curam communitatis habet.

A pesar de estas connotaciones teológicas de los orígenes del derecho de resistencia, interesa también resaltar que, desde un principio, es concebido como un derecho de los súbditos frente a los actos desviados del poder. Por otra parte, no se puede olvidar que este carácter, el de un derecho de protección contra el poder, persistirá con el paso del tiempo, sustentando posiciones muy diversas, pero que claramente beberán de la misma fuente.

El derecho de resistencia ofrecía, por tanto, una tipología enrevesada y casi acomodable al proyecto de cada autor. La institución era ciertamente difícil de defender; más aún cuando resultaba molesta para un poder político cuyos títulos de legitimidad aún no habían sufrido una valoración racionalista. Había que andarse con cuidado, aún con la protección dispensada por la teología; ello explica los cuidados, cautelas y reservas mostradas por los juristas y teólogos al enfrentarse a esta institución sobre la que, por otra parte, pocos eran los que dudaban en poner el granito de arena de su propia reflexión.

Por su parte, la Escolástica hispana se caracterizó por una extrema ponderación de circunstancias de las que era difícil sacar principios de aplicación general, a no ser excesivamente abstractos. Esa será, precisamente, la posición del mismo Francisco Suárez y, de manera más radical aún, de Juan de Mariana (De Mariana, pp. 92105).

El derecho de resistencia ofrecía una tipología rica en detalles que afectaban a la forma de su ejercicio y a la manera o titularidad para llevarlo a cabo. La cualidad dependía de la clase de ilegitimidad en la que el tirano hubiera incurrido. De manera concreta, se entendía por ilegitimidad de origen, la ejercida por un usurpador que se había apoderado del poder sin justos títulos. Esta expresión autorizaba con mayor facilidad el ejercicio de resistencia a cualesquiera de los componentes de la comunidad política, ya que se trataba de reparar la violación del Derecho y atentar contra quien se había puesto voluntariamente fuera de la ley de Dios y de los hombres.

Por su parte, la ilegitimidad de ejercicio pedía mayores cautelas y títulos, puesto que el poder era ejercido de un modo tiránico, pero por quien poseía justos títulos 
para estar al frente de la comunidad. En tal caso era necesaria una especial designación de personas cualificadas para resistir al poder, singularmente cuando la resistencia concluía con la práctica del tiranicidio. La forma y el procedimiento de ejecución de la resistencia eran una derivación de la propia magnitud de la tiranía; si no había otro remedio para atajar la degradación de la situación política se podía llegar a la muerte del tirano. Una atención a las circunstancias del momento y a las posibilidades de éxito de la resistencia provocaba que los juristas entraran en un detallado casuismo que podía ser solucionado por el criterio general propuesto por santo Tomás de Aquino: “... si el tirano no comete excesos, es preferible soportar temporalmente una tiranía moderada que oponerse a ella, porque tal oposición puede implicar peligros mayores que la misma tiranía" (Tomás de Aquino, La monarquía: Al rey de Chipre, lib. I, cap. 6).

El tránsito a la Modernidad suponía también retomar el derecho de resistencia para insertarlo en el proyecto liberal de defensa de las libertades individuales, que serán luego reconocidas en las declaraciones y constituciones de los siglos XVII y XVIII. Puede incluso resultar extraño que el ius resistendi, apoyado en la lex divina y en la lex naturalis durante el Medioevo, pretendiera ser una defensa contra las disposiciones de los príncipes tiranos. Posteriormente, el derecho de resistencia, que antes había estado fundamentado en la ley natural, se apoyará en el derecho natural racionalista.

El propio Calvino se planteaba "en qué medida y cómo resistir a la tiranía de ciertas autoridades” (Calvino, 1981, p. 1193 [IV, 32]), así como los "límites impuestos por Dios a nuestra obediencia a los hombres" (Calvino, 1981 pp. 1193-1194 [IV, 32]), temas que estudia en los dos últimos capítulos de su Institución. Entiende que la tiranía la debe sufrir el creyente como una ocasión de aprendizaje espiritual. Ya Dios, como demuestran los hechos de la historia, levantará otro poder que derribe al tirano; no perteneciendo a la vocación de alguien, que no sea magistrado, intervenir con la intención de derribarlo. Pero ya que en el orden civil existen escalones de gobierno, aquellos que los ocupan sí pueden frenar o eliminar al tirano, lo que correspondía a los magistrados inferiores que tendrían la obligación de defender el derecho del pueblo injustamente oprimido por los reyes.

El principio básico que sustenta su argumento era que la obediencia debida a los hombres no lo aparte de la que también corresponde a Dios. Calvino considera que la acción tiránica invalida el ejercicio de autoridad civil de quien la ejerce, por lo tanto, la resistencia no es contra la autoridad.

Lutero había entendido la acción de la autoridad secular como legítima en la represión de la rebelión campesina. Concede el derecho a la legítima defensa, a resistir frente a los derechos que reclaman los grupos rebeldes; pero qué sucedía si la rebelión era propuesta por dos autoridades seculares. Lógicamente el dirimir dicha cuestión debía venir sustentado en la opción por la causa más justa, a la que se llegaría por medio de la razón.

Pocos años más tarde, la reforma religiosa había llegado ya a diversos territorios y ciudades, ya fuera por motivos religiosos o intereses políticos, poniendo de manifiesto que el modelo de resistencia propuesto por Lutero -el del providencialismo pasivo- ya no respondía a la nueva situación. Él mismo se preguntará cómo habían de responder los príncipes que habían tomado en sus territorios la dirección de la reforma religiosa, si en su momento se presentaba una Liga armada de papistas que quisiera obligarles a volver a la situación anterior, a la obediencia a Roma. La respuesta de los reformadores es que algunos príncipes, incluso en su condición episcopal, vienen en nombre del emperador para reimplantar la catolicidad, abriendo el debate sobre la posibilidad legal de resistirse, dejando así la puerta expedita para una defensa armada; pues entendían que se estaba actuando con toda justicia y rectitud frente al tirano.

Junto a la posición de aquellos que seguían la opinión de Lutero - que tendía a una interpretación de signo pacifista-, se encontraban cada vez más aquellos que considerarán que existen otras vías para que un príncipe territorial pueda usar la espada contra la autoridad que pretendía destruir la religión, por entender que era algo vital para su gente. La intervención del emperador, con 
el Edicto de Worms, precipitó la toma de posiciones. Los príncipes y ciudades reunidos en la Liga de Esmalcalda asumieron el derecho a defender a sus súbditos contra la pretensión de volver a la obediencia de Roma.

La reflexión adquirió vías razonables cuando se trataba de la oposición armada a los príncipes católicos, aunque dijeran venir en nombre del emperador. Eran los príncipes católicos los que, al luchar contra la Reforma, se constituían en enemigos del bien del imperio. Los luteranos conservaban así la idea del imperio, con el emperador como su legítima autoridad suprema, cuya conservación y existencia se asumía como propia de la misma historia de la humanidad. Mucho más difícil era explicar la situación en la que el mismo emperador se presentaba como la autoridad contra la que había que usar la espada.

Lutero que por otra parte había encontrado un argumento fácil para calificar la rebelión de un grupo de campesinos contra la legítima autoridad de su señor, se amparó, en esta ocasión, en el dictamen de los juristas y teólogos ante la rebelión de un grupo de señores contra la legítima autoridad de su emperador. No cabe duda de que, al hacer referencia a estos dos contextos significativos de la Reforma, por parte de Suárez, se pretende poner de manifiesto la arbitrariedad y, por tanto, la tiranía del soberano inglés, al imponer el iuramento fidelitatis. El cambio no se produce solo en la finalidad, sino que afecta asimismo la validez de este derecho, pues ya deja de ser una doctrina jurídica para convertirse en un derecho jurídico-positivo, como se pone de manifiesto en los casos concretos.

\subsection{Entre el "Juramento" de Jacobo I y la "Defensio" de Suárez}

La defensio fidei plantea, desde una visión teológicocanónica, una respuesta coherente a los intereses de la Iglesia, entendiendo que miraban al conjunto de la sociedad, por las estrechas implicaciones que tenía en la organización y surgimiento de los diversos Estados, que ahora se iban desgajando, en razón de la progresiva influencia y beligerancia de la Reforma y de sus seguidores. Esa realidad, el jesuita la plantea en el análisis atento de lo que él considera como los tres problemas fundamentales: la conciencia individual, las relaciones del Estado con la Iglesia y las relaciones del poder con el pueblo (Suárez, 1979, De iuramento fidelitatis VI, 5-7, pp. $109-112)^{26}$.

El absolutismo y despotismo pretendían adueñarse de dicha conciencia, como si de un arma invencible se tratase, desde la cual controlar y dirigir al pueblo en sus múltiples decisiones. El juramento de fidelidad afectaba más a las relaciones Iglesia-Estado que al pueblo, que seguía al soberano sin crearse mucho problema, pero abría una puerta que difícilmente podría ser cerrada, dejando poco margen de movimiento para devolver las cosas al estado anterior. Precisamente por ello, Suárez se preocupó del problema de la conciencia, entendiendo que era una cuestión esencial y que de no ser abordada, tendría unas consecuencias sociales y de trascendencia difícilmente salvables. Planteaba y removía incluso la visión antropológica y, por lo mismo, el concepto de hombre que se proyectaba y se defendía. Hacer caso omiso y permitir injerencias como las de Jacobo I, suponía negar elementos esenciales de la visión cristiana del hombre, que había incluso permitido proponer y hacer efectiva una distribución social, que no era la típica de la tradición greco-romana, sino que había roto con los principios de una distribución social de clases.

La violencia con que se aplicó el juramento abrió un nuevo capítulo en la historia de las persecuciones inglesas y el martirologio inglés. Belarmino y Suárez defendieron este carácter martirial de la muerte por resistir a la prestación del juramento. Algo que harán todos los teólogos de su tiempo y que claramente proyectaba la interrelación de diversos niveles de vida.

\footnotetext{
${ }^{26}$ En estos capítulos responde a Jacobo I, entendiendo que el título del juramento demuestra que este es arbitra-rio, pero con una intención precisa; el poder identificar a los católicos, en aquellos reinos. Además, teniendo en cuenta el anterior juramento, se pone de manifiesto que la intención del soberano es ocupar el primado en el ámbito religioso y, por lo mismo, renegar del poder del papa. Por último, Suárez se detiene en identificar la terminología errónea y manipulada, al tiempo que, nuevamente, afirma que el poder civil ha de estar subor-dinado al religioso.
} 
Lo peculiar del juramento de Jacobo I era su propuesta e intento de pasar de lo institucional, como era común en los problemas medievales, a ser algo personal y unilateral transformado en instrumento del engrandecimiento regio. Un soberano con poderes casi absolutos que incluso podía disponer de la vida o muerte de sus súbditos, y todo ello justificado a partir de sus creencias religiosas, así como de los comportamientos ético-morales deducibles de las mismas, que tenían en la conciencia recta la máxima expresión de la misma.

En razón de su proceder, en el que no se respeta siquiera lo más íntimo de los espacios alternativos y propios, Jacobo I será considerado como aquel que vuelve a dividir la Cristiandad, haciendo del juramento un vínculo por el cual quedarán los príncipes cristianos conjurados en una guerra común contra la unidad de la Iglesia representada por el papa. Por lo mismo, no era solo un intento por ampliar los seguidores de su causa sino que, de manera activa, era un enfrentamiento manifiesto hacia Roma y la catolicidad. No era ya posible siquiera una reconciliación política, puesto que se entendía que la religión caminaba también de la mano. Al fomentar la parcelación religiosa de Occidente, Jacobo I estaba modificando el concepto clásico de pueblo. La sociedad clásica medieval que era unitaria y jerárquica, aparecía transformada en razón de dicho juramento. El centralismo de Jacobo I, además, se sustentaba sobre el debilitamiento de la nobleza y de la Iglesia, por lo cual se rompía el principio clásico que había mantenido el antiguo régimen, que se basaba en la compensación de poderes, no permitiendo que la fuerza recayera en un solo individuo, aunque este fuera el propio rey de Inglaterra.

Suárez denunciará atentamente el peligro de una política absolutista; pero Jacobo I y aquellos que le siguen no se harán problema de la razón del traslado y uso de lo religioso para la política de Estados sin comprender sus matices y consecuencias posibles, desprestigiando de hecho la Defensio fidei del jesuita.

Bajo la unidad del Sacro Imperio, controlado primero por los papas, y después con el equilibrio de fuerzas del Renacimiento, los pueblos adquirieron conciencia de constituir una potencia capaz de actuar en la política, dominada clásicamente por la realeza y el sacerdocio.
La consecuencia concreta será que la persecución de Jacobo I no fortalecerá la monarquía, sino que la dejará al descubierto, en razón de haberse esta opuesto radicalmente al contrapeso de la nobleza frente al pueblo.

Lo singular de Suárez será su audacia para entreverar la fuerza social del pueblo. Su teoría sobre la ordenación político-social corona las discusiones medievales de la Iglesia y del Imperio. Por su parte, Jacobo I extremará la tesis imperialista, defendiendo la supremacía civil y religiosa de la Corona inglesa contra los decretalistas pontificios capitaneados por la postura doctrinal de Enrique de Suso, el cardenal Ostiense, que hacían del papa jefe supremo del universo en lo temporal y en lo eclesiástico. Eran dos posturas que no lograrían un punto de encuentro desde el cual dialogar.

Suárez recogió las enseñanzas de la tradición cristiana y primitiva, siguiendo a Francisco de Vitoria, deduciendo hasta el fin la distinción entre los derechos políticos de los pueblos organizados en Estados y de las naciones estructuradas con nuevas organizaciones sociales comunitarias, como se habían conocido en Castilla y en el Occidente antes de la invasión romana; reiterándose una situación similar en el Norte de España con el hundimiento de la monarquía visigoda.

En su Principatus politicus, Suárez se basa en el conocimiento que tiene de las vicisitudes históricas de la organización social primitiva peninsular. Las organizaciones prepolíticas occidentales serán las que den sentido a la propuesta por Suárez en su Defensio. Por lo mismo, frente a la publicación de su obra, en 1613, Jacobo I comenzará una nueva campaña de ataque directo a Roma. Precisamente por ello, promoverá que la obra de Suárez sea refutada por los doctores de Oxford, conjuntamente con la de Belarmino, y fue también quemada en Londres y prohibida en toda Inglaterra. Los impresos hacían caminar las ideas y llegar hasta espacios privados difícilmente controlables por el poder. La justificación de quemar la obra será en razón del tiranicidio, aunque esta no era la única razón. Gerson y la Sorbona habían mantenido tesis bastante próximas, pero no habían generado problema y serían defendidas en 1561, por Tanquerel en aquella Academia. 
El absolutismo de Jacobo I y de la Corte de Francia exigía del pueblo la plena impunidad para los desafueros regios. Suárez argumentaba la invulnerabilidad del derecho, contra todo delito, tanto del pueblo como de la realeza. Las posiciones defendidas por Jacobo I exigían y asediaban a la nobleza por diversos propósitos, generando conflicto con el pueblo, en virtud de unos fines superiores y absolutos, al amparo del pensamiento tradicional de la Iglesia. Las ideas de Suárez, con gran éxito, servirán para justificar actitudes por medio de las cuales romper el poder establecido.

Por contraposición a la postura del soberano, el concepto suareziano de pueblo se mantenía en los principios eternos y absolutos de la sociabilidad humana (Suárez, 1965, Defensio fidei II, 3-4, pp. 17-18; Suárez, 1979, De iuramento fidelitatis V, 2, pp. 98-99). El pueblo como tal, prescindiendo de toda configuración política, y entendido en toda su universalidad conforme a la revelación cristiana, tenía un valor anterior a la autoridad humana e independiente de ella. Y, en línea de principios, al perfeccionamiento social progresivo en el orden natural debían servir como medios las diversas estructuras políticas y jerárquicas. La autoridad, por tanto, había sido puesta por Dios en la naturaleza y en la historia para fomentar en el pueblo la unidad total del reino de Dios, sometida al único poder absoluto en el dominio de Dios ${ }^{27}$.

Jacobo I se equivocaba al creer que bastaba la obediencia del pueblo y el poder del soberano para regir a los hombres. La persecución contra la nobleza católica adquirió en lo político y religioso proporciones terribles y cada vez más alarmantes, mostrando que se habían roto todas las normas de organización social. Francisco Suárez tendrá la oportunidad de irlo analizando progresivamente en las arduas gestiones que precederán a la composición de la Defensio fidei en contacto con la Sede Apostólica, con Belarmino y con la Corte de Castilla; así como en los escritos y acciones concretas del monarca inglés (Baciero 1979; García, 1979).

La contestación social podría ser entendida como la manifestación de la disidencia contra determinadas normas o actuaciones de los poderes públicos, sin traspasar el marco de la legalidad. La contestación perseguía los mismos objetivos de la desobediencia civil, al tiempo que deseaba hacer públicos los motivos de la disidencia, pero sin sobrepasar los límites de la legalidad.

La Defensio fidei solo puede ser comprendida, a partir de las posiciones de Suárez frente a los diversos planes y personajes que influyeron en el drama de la separación religiosa y política de Inglaterra. En el fondo del problema teológico se debatía una cuestión social y política, que Jacobo I resolvía a su favor considerando el poder regio como soberanía personal y absoluta otorgada por Dios inmediatamente al rey. Suárez, frente a esta postura, defendía la tradición medieval que entendía que la potestad política era otorgada por Dios directamente al pueblo, y por este a los gobernantes ${ }^{28}$.

La doctrina de la soberanía popular, así entendida, la desarrollará en los capítulos segundo y tercero del libro III de la Defensio. Suárez parece argumentar con bastante objetividad, precisamente por ello no tiene problema en llegar a afirmar lo que sigue:

... hay que decir que los reyes cristianos tienen el poder político supremo en su orden y que directamente no reconocen a ningún superior dentro del mismo orden temporal o político, del que dependan formalmente en los actos propios de su poder. En conclusión, no se da en la Iglesia un único gobernante que sea políticamente soberano sobre toda la Iglesia o todos sus reinos, sino que existen tantos soberanos cuantos son los reinos o repúblicas independientes. Esta es la tesis más aceptada y recomendada entre los católicos (Suárez, 1965, Defensio fidei V, 6, pp. 73-74).

\footnotetext{
27 “... hac ratione terreni reges ministri Dei vocantur in Scriptura, ut vidimus; ergo eorum potestas ministerialis est respectu Dei; ergo ipse est principales auctor huius regiminis" (Suárez, 1965, Defensio fidei, I, 7, p. 12).

${ }^{28}$ Se fundamentaba v. gr., en la tradición castellana medieval de las Cortes, Concejos y Municipios, y que el jesuita había asimilado en línea con toda la Escuela española del derecho (Elliot, 2006, p. 594).
} 
En el prefacio, Jacobo I achacaba a los romanos pontífices $^{29}$ la arrogación de un poder de matar arbitrariamente, posse ad libidinem a los reyes, usurpación intolerable contra la cual ha resistido el poder civil continuamente desde los emperadores bizantinos, pasando por los carolingios, los germanos y franceses a los monarcas ingleses. En esta resistencia se funda la primacía de la Corona inglesa aun en lo espiritual. Suárez probará que estas son situaciones esporádicas, frente a aquellos que lo aceptaran de buena fe.

Quién ha recibido de Dios los poderes espirituales que ostenta, el papa o el monarca inglés. Suárez afirma que en este punto nada resuelve la conducta humana. Jacobo I opina que la prescripción crea aquí derecho, de igual manera que en cualquier otro campo. Es claro que parten de visiones distantes, acerca del concepto de derecho natural. Para Jacobo I, derecho natural es la imposición de los hechos naturales consumados, sin relación ética, como es el nacimiento regio, la ocupación primera de la tierra o la invasión triunfante de otro principado.

Suárez entiende el derecho natural como la determinación de la razón o del logos inmanente respecto al mundo. Se trataría de la concepción primitiva o auténtica del derecho occidental, que podría estar representada por Séneca, y que tendría su continuidad en el derecho canónico, los códigos medievales y, en el siglo XVI, en la aportación singular de Francisco Suárez ${ }^{30}$. Por encima de lo político y de la ratio cósmica, habría un orden jurídico moral, impuesto por la voluntad libre del Creador. Dentro de este orden jurídico se señalan los derechos y obligaciones, no por el mero hecho natural de ser uno sujeto de derecho, sino por la promulgación multiforme de la ley, en razón de un sistema de requerimientos, por títulos adecuados para cada uno de los derechos y obligaciones.

Jacobo I no admitirá estos títulos jurídicos. Para él no hay más que hechos consumados. En esta doble posición, aunque Suárez y Jacobo I parecen estar refiriéndose y hablando de las mismas cosas, al tratar de la familia, de la autoridad, del pueblo... en realidad hablan de cosas distintas. Es esta, quizás, la cuestión que más convenga poner en evidencia. Jacobo I solo se refiere a objetos y acciones palpables físicamente. Suárez, por el contrario, habla de una organización jurídica o social, que podría ser natural y sobrenatural, a la cual había de pertenecer el juramento de fidelidad. Para Jacobo I el juramento no es más que un nuevo recurso al servicio del poder.

\subsection{La singular y polémica aportación de Suárez}

Suárez hace un análisis atento del juramento, en el libro VI de su Defensio fidei. Al igual que Belarmino, tampoco él cuestiona la posibilidad de prestar dicho juramento ${ }^{31}$. La refutación del jesuita comienza por la segunda parte del último juramento inglés. Tiene conciencia de que se está atentando contra los derechos de la Iglesia. Así, el juramento de fidelidad, lo toma de la copia existente en el primer breve pontificio de Paulo V, aduciendo tres fórmulas: la primera de la reina Isabel y las dos de Jacobo I. Se atenta contra los derechos de la Iglesia al obligar a los súbditos a revelar toda clase de conspiraciones y atentados contra el rey y sus sucesores. No se respeta su privacidad, aunque pudiera esto quedar encubierto, a partir del principio del bien común.

La cláusula tercera del juramento se refiere, concretamente, a la potestad pontificia de deponer y

\footnotetext{
29 “... credo et in conscientia mea resolvor quod nec Papa, nec alius quicumque potestatem habet me ab hoc iuramento aut aliqua eius parte absolvendi". Jacobo I, "Tertia iurandi formula, quae a rege lacobo fuit excogi-tata et defensa" (Suárez, 1979, De iuramento fidelitatis, p. 23).

${ }^{30}$ Suárez, apoyándose en Isidoro de Sevilla, sostendrá que el derecho de gentes difiere esencialmente del derecho natural, pues mientras el derecho natural es común a todos los hombres y nunca puede dejar de observarse, el de gentes no es observado siempre y por todos los pueblos, sino de ordinario y por casi todos (Suárez, 1856, De legibus, IV, cap. 19, nn. 1-3, pp. 124-129).

31 "De primo genere iuramenti (ut dixi) nulla est inter Pontificem et regem Angliae controversia. Quantumvis enim rex iniuriam et iniustitiam sibi fieri a Pontifice conqueratur, prohibendo subditis suis ne obedientiam civilem illi promittant et servent, revera non ita est, ut merito notavit Bellarminus in responsione ad Praefa-tionem regiam (cap. 2) et in Apologia respondendo ab obiecta contra primum Breve Pontificis (§ Pergit deinde auctor, etc.)" (Suárez, 1965, Defensio fidei VI, 1,2, p. 33).
} 
aun de dar muerte a los príncipes excomulgados. Suárez condenará la muerte dada por autoridad privada al régimen tiránico, reservando esas sanciones a la autoridad pública $^{32}$. En respuesta a lo que pretendía Jacobo I, que quería que se le discutiese por partes y minuciosamente, Suárez afrontará dicho reto con atención y perspicacia. No sólo se centra en refutar lo expuesto en el juramento, sino que estudia el problema planteado por la misma prestación de un juramento de fidelidad de súbditos cristianos a un monarca heterodoxo. Era un aspecto significativo del derecho político, puesto que el hecho en sí le quitaba toda la credibilidad al monarca.

Jacobo I, en su intento apologético, formula tres objeciones basadas en inconvenientes morales. Paulo V obligaba primeramente a sus súbditos a ir contra el rey. Los ponía en la alternativa de sufrir las mayores calamidades, con la pérdida de la fortuna y de la misma vida. Condenaba el juramento en forma tan categórica que hacía imposible todo compromiso con el rey y toda excusa respecto de los católicos que lo rechazaran.

Con el fin de poder asentar dichos principios, Jacobo I negará al papa la competencia para dirimir el pleito suscitado entre la potestad civil y la eclesiástica. Era claro que el papa debía y podía dirimir el pleito, pues así había sido defendido tradicionalmente por el derecho canónico, en relación a la culpabilidad moral de los creyentes que prestaban un juramento de fidelidad reprobado por el Papa (Suárez, 1965, Defensio fidei, VI, 7,8, pp. 136137). Suárez considerará que después de la intervención pontificia, que un católico prestase el juramento era algo manifiestamente ilícito ${ }^{33}$. Su posición llevará a que el propio Jacobo I se justifique, haciéndolo también a partir de la autoridad de los concilios, aunque Suárez le hará notar como los utilizados por él no corresponden verdaderamente a los temas a los que se está refiriendo él en su juramento (Suárez, 1965, Defensio fidei VI, 12,8, p. 250).

Mientras que el monarca inglés está manteniendo la polémica en un ámbito político-religioso, generando una discusión que iba dirigida al papa -identificado en Paulo $\checkmark$ y en el propio Belarmino-; Suárez intenta llevar la discusión al campo doctrinal, en lo que entra en la propia apologética de defensa del papado. Tanto Jacobo I como Francisco Suárez intentarán argumentar a partir de la Escritura. La diferencia será significativa. El soberano inglés utilizará aquellos textos que le sean favorables y que le permitan confirmar sus pretensiones. La Escritura será un medio normativo de conducta individual y justificación del poder, haciendo una interpretación abiertamente subjetiva y variable.

A Jacobo I no le preocupa la organización de un sistema doctrinal, por ello pone el acento en el desacuerdo básico entre las dos posturas que se encuentran en el respectivo concepto que cada uno tiene del derecho natural, así como en su aplicación al derecho positivo. Según Jacobo I los derechos de la naturaleza se fundamentan en el hecho natural de tener sangre regia ${ }^{34}$ y en esta manera de argumentar se basaba también el desarrollo que obtendría el derecho político, raíz de los derechos del monarca sobre el reino. Jacobo I formula su teoría política, basándose en el modelo del matrimonio. Así, en el primer discurso pronunciado en el Parlamento inglés, hablando de la unión indisoluble existente entre el monarca y los reinos unidos de Escocia e Inglaterra, pondrá ese ejemplo, haciendo un uso bastante forzado de la ley canónica. Las relaciones entre el monarca y el reino, entiende que son tan naturales como las del esposo y la esposa. El papel del pueblo, lo mismo que

\footnotetext{
32 “... in hoc vero est magna differentia inter hunc et regem pravum. Nam rex licet tyrannice gubernet, quamdiu non movet actuale bellum iniustum contra rempublicam sibi subditam, non infert illi actualem vim, et ideo respectu illius non habet locum defensio, neque ullus subditus potest hoc titulo illum aggredi aut bellum contra ipsum movere. At vero proprius tyrannus quamdiu regnum iniuste detinet et per vim dominatur, sem-per actu infert vim reipublicae, et ita ipsa Semper gerit cum illo actuale seu virtuale bellum, non vindicati-vum, ut sic dicam, sed defensivum" (Suárez, 1965, Defensio fidei VI, 4,13, p. 84).

33 "... quia verba iuramenti semper fuerunt tam perspicua et tam multiplicia et tot modis conscientiam illa-queantia et schismatis approbationem et professionem inducentia, ut licet in una vel alia vocula aut particula, colorata evasio locum habere potuerit, impossibile fuerit modum vere probabilem invenire totum iuramentum honestandi seu excusandi ac pericula eius evadendi, ut satis probant quae de singulis eius verbis hactenus ponderata sunt" (Suárez, 1965, Defensio fidei VI, 8,15, p. 156).

${ }^{34}$ Su argumentación se acercaría a la de Calvino, pues para ambos no existiría una comunidad natural que se pudiera elevar al orden sobrenatural.
} 
el de la esposa, es puramente pasivo dentro de las relaciones político-conyugales, mostrando que las leyes son las que orientan y ordenan la manera de proceder (lacobo I, 1635, p. 91).

El mismo soberano no era ingenuo, por lo que pretendía también hacer aparecer aquello que había sido la visión tradicional de las tareas que correspondían al gobernante: "Administra justicia, pero atemperada con tal moderación, que no degenere en tiranía. Porque de lo contrario el Derecho Supremo, muchas veces, es la suprema injusticia" (lacobo I, 1635, p. 90).
Entendía que las relaciones políticas entre monarca y pueblo se basan en el fenómeno biológico del nacimiento. Lo que llevaba implícitamente a considerar que no había obligaciones de tipo bilateral. El rey gozaba sobre el pueblo de todos los derechos, sin otra contrapartida que la cuenta que ha de dar ante Dios de su administración. Consideraba que la dignidad real es "a la vez civil y eclesiástica. El rey no es un simple laico, como lo quisieron los papistas, anabaptistas y puritanos" (p. 71). De aquí se justificaba que pudiera ostentar el título de primacía espiritual, como algo ajeno a la Corona inglesa. Los vasallos no tienen más función que la obediencia al déspota impuesto por Dios.

\section{Referencias}

Baciero, C. (1979). Polémica entre Jacobo I de Inglaterra y Roberto Belarmino. En L. Pereña, V. Abril, C. Baciero, A. García, F. Belda, F. Maseda y C. Villanueva (Eds.). Francisco Suárez. De iuramento fidelitatis. Estudio preliminar. Conciencia y politica (pp. 341-445). Madrid: CSIC.

Calvino, J. (1981). Institución de la religión cristiana II (1556). (2a ed.). Rijswijk: Fundación editorial de la literatura reformada.

Cosi, G. (1984). Saggio sulla disobbedienza civile: Storia e critica del disenso in democracia. Milano: Giuffrè.

De Mariana, J. (1981). La dignidad real y la educación del rey (De rege et regis institutione). En L. Sánchez Agesta (Ed.). Madrid: Centro de Estudios Constitucionales.

Elliot, J. H. (2006). Imperios del mundo atlántico: España y Gran Bretaña 1492-1830. Madrid: Taurus.

García y García, A. (1979). El juramento de fidelidad de los concilios visigóticos. En L. Pereña, V. Abril, C. Baciero,

A. García, F. Belda, F. Maseda, C. Villanueva (Eds.). Francisco Suárez. De iuramento fidelitatis. Estudio preliminar. Conciencia y politica (pp. 447-490). Madrid: CSIC.

lacobo I. (1979). Fórmula del juramento. En L. Pereña, V. Abril, C. Baciero, A. García, F. Belda, F. Maseda, C. Villanueva

(Eds.). Francisco Suárez. De iuramento fidelitatis. Estudio preliminar. Conciencia y política (pp. 517-523). Madrid:

CSIC.

lacobo I. (1609). Apologia pro luramento Fidelitatis. Londini: excudebat loannes Norton.

lacobo I. (1635). Basilikon doron. Frankfurt.

Suárez, F. (1856). Tractatus de Legibus, Opera Omnia (Editio nova), C. Berton (Ed.). Parisiis Vivès, vol. 5-6.

Suárez, F. (1965). Defensio fidei. Principatus politicus o la soberanía popular. E. Elorduy y L. Pereña (Eds.). Madrid: CSIC.

Suárez, F. (1978). De iuramento fidelitatis. Documentación fundamental. En L. Pereña, V. Abril, C. Baciero, A. García,

F. Belda, F. Maseda y C. Villanueva (Eds.). Madrid: CSIC.

Suárez, F. (1979). De iuramento fidelitatis. Estudio preliminar. Conciencia y politica. En L. Pereña, V. Abril, C. Baciero,

A. García, F. Belda y F. Maseda y C. Villanueva (Eds.). Madrid: CISC.

Tomás de Aquino (1989). Suma Teológica, Madrid: BAC.

Tomás de Aquino (2003). La monarquía: Al rey de Chipre. En Opúsculos y cuestiones selectas. Edición bilingüe.

Madrid: BAC. 